\title{
Association between serum alanine and aspartate aminotransferase and blood pressure: a cross-sectional study of Chinese freshmen
}

Lijun Zhu ${ }^{1,2 \dagger}$, Zhengmei Fang ${ }^{1,2 \dagger}$, Yuelong Jin ${ }^{1,2}$, Weiwei Chang ${ }^{1,2}$, Mengyun Huang ${ }^{1,2}$, Lianping $\mathrm{He}^{3}$, Yan Chen ${ }^{1,2^{*}}$ and Yingshui Yao ${ }^{1,2,4^{*}}$

\begin{abstract}
Background: High blood pressure is a well-recognized risk factor for cardiovascular events, and the incidence of hypertension is increasing among young people. This study investigated the relationship between ALT and AST levels and hypertension among freshmen in China.

Methods: This cross-sectional study was conducted in the Anhui Province from September to November 2018. A total of 3114 freshmen underwent a physical examination including testing of biochemical indicators and a standardized questionnaire.

Results: The overall prevalence of elevated ALT and AST were 6.8\% and 2.3\% among freshmen. The mean ALT and AST levels were higher in males ( $22.59 \pm 21.98$ vs. $12.62 \pm 10.30 \mathrm{U} / \mathrm{L} ; 23.55 \pm 12.24 \mathrm{Vs}$. $20.02 \pm 5.75 \mathrm{U} / \mathrm{L}$, respectively). The prevalence of hypertension was significantly higher in men (16.1\%) than in women (1.9\%). The mean values of BMI, SBP, DBP, TC, TG, and LDL-C were found to be increased with elevated levels of serum ALT and AST in the quartiles ( $P$ for trend $<0.05$ ). After adjusting for covariates, the risk of hypertension was significantly higher in the highest ALT quartile than in the lowest quartile (OR $(95 \% \mathrm{Cl})$ of $1.681(1.028,2.751)$ in males; $2.802(1.102,7.124)$ in females). A strong linear relationship was found between serum ALT levels and the odds of hypertension after adjustment for potential confounders only in total population and females ( $P$ for trend $<0.05$ ).
\end{abstract}

Conclusions: These findings suggest that ALT level is significantly associated with hypertension both in male and female freshmen.

Keywords: Alanine aminotransferase, Aspartate aminotransferase, Freshmen, Hypertension, Association, Crosssectional

*Correspondence: bingyan-1209@163.com; yingshuiyao@126.com

${ }^{\dagger}$ Lijun Zhu and Zhengmei Fang have contributed equally to the work

1 Department of Epidemiology and Biostatistics, School of Public Health,

Wannan Medical College, No. 22, Wenchang Road, Wuhu 241002, Anhui,

China

Full list of author information is available at the end of the article

\section{Background}

Cardiovascular diseases are responsible for more than 18 million deaths each year, accounting for approximately one-third of all global deaths [1]. High blood pressure is a well-recognized risk factor for cardiovascular events. Although hypertension is traditionally more prevalent in older people, recent epidemiological studies have shown an increased prevalence of risk

(c) The Author(s) 2021. Open Access This article is licensed under a Creative Commons Attribution 4.0 International License, which permits use, sharing, adaptation, distribution and reproduction in any medium or format, as long as you give appropriate credit to the original author(s) and the source, provide a link to the Creative Commons licence, and indicate if changes were made. The images or other third party material in this article are included in the article's Creative Commons licence, unless indicated otherwise in a credit line to the material. If material is not included in the article's Creative Commons licence and your intended use is not permitted by statutory regulation or exceeds the permitted use, you will need to obtain permission directly from the copyright holder. To view a copy of this licence, visit http://creativecommons.org/licenses/by/4.0/. The Creative Commons Public Domain Dedication waiver (http://creativeco mmons.org/publicdomain/zero/1.0/) applies to the data made available in this article, unless otherwise stated in a credit line to the data. 
factors in the young, including obesity, diabetes mellitus, and renal disease, and the incidence of hypertension is progressively rising among the young [2]. Moreover, the younger the onset of hypertension, the higher the risk of cardiovascular disease and all-cause mortality [3]. Recently, some epidemiological studies suggest liver enzymes such as alanine and aspartate aminotransferase (ALT, AST) are associated with the presence of hypertension [4,5]. ALT and AST are sensitive indicators of liver cell injury and have been used to identify patients with liver disease. A case-control study in China has showing ALT is a potential indicator for patients with hypertension in senior adults [6]. A 12-year Korean Cohort Study reported that progression to hypertension was associated with frequent drinking and high ALT levels among men [7]. Moreover, previous work from the Framingham Heart Study found that increased ALT levels were associated with elevated blood pressure, and higher AST levels were correlated with higher DBP [8]. Inconsistent with previous studies, Gupta et al. [9] reported no significant relationship in the ALT and AST levels of normal, prehypertensive, and hypertensive individuals. However, most of the previous studies assessed the relationship that included only in adults and their findings were inconsistent. There are scarce earlier studies of this association among young people.

Freshmen generally experience substantial changes including the transition from high school to university, changes in living environment, lifestyle, and life content. A survey in Lebanon found that the students gained approximately $1.90 \mathrm{~kg}$ when transitioning from high school to university and significant increases in waist circumference, blood glucose, and triglyceride levels were detected [10]. An entry health examination of college students in North Taiwan shows that the prevalence of abnormal liver function tests was $6.2 \%$ among freshmen [11]. A meta-analysis on the prevalence of hypertension among college students in China shows that $3.62 \%$ of college students suffer from hypertension [12]. Another study of university students aged 15-19 in Nigeria showed that the prevalence of hypertension was $25.1 \%$ [13]. The epidemiological data concerning the association between elevated ALT and AST and hypertension in the Chinese freshmen are not available yet. In view of the relationship between liver enzymes and blood pressure in adults, the study of liver enzymes in adolescents may have guiding significance for mitigating the risk of hypertension among adolescents.

This study aimed to investigate whether there is a relationship between ALT and AST and the occurrence of hypertension among freshmen in China.

\section{Methods}

\section{Study population}

A population-based cross-sectional survey was conducted at a medical college in Anhui, China between September and November 2018. A total of 3450 freshmen were investigated. Another 101 individuals with missing height or weight and 235 individuals with missed questionnaires and associated information were excluded. Ultimately, 3114 freshmen were included in the final analysis. The study was approved by the Ethics Committee of Wannan Medical College, Yijishan Hospital (Approval No. 32 (2018)). Written informed consent was obtained from all participants or, if subjects are under 18, from a parent and/or legal guardian.

\section{Data collection and measurements}

Each participant completed a standard questionnaire and underwent a detailed physical examination by a trained doctor or nurse. Physical examination included the following procedures. Blood pressure was measured twice with an interval of no less than 2 min with a mercury sphygmomanometer (Omron U30, China), with the participants in a sitting position and after at least $5 \mathrm{~min}$ of rest. The average value of the two measurements was taken as the final BP. The height and weight of the subjects were measured using an ultrasound height and weight measuring instrument (Shengyuan, China), with the participants in light clothing and without shoes, in an upright position. Waist circumference was measured $1 \mathrm{~cm}$ above the umbilicus in a horizontal plane. Body mass index (BMI) was calculated by dividing weight $(\mathrm{kg})$ by height $(\mathrm{m})$ squared $\left(\mathrm{kg} / \mathrm{m}^{2}\right)$.

Venous blood samples were collected in the morning after at least $10 \mathrm{~h}$ of overnight fasting. The serum samples were separated for biochemical assays without freezing. Biochemical variables, including serum ALT, AST, triglyceride (TG), total cholesterol (TC), high-density lipoprotein cholesterol (HDL-C), low-density lipoprotein cholesterol (LDL-C), and glucose (GLU) were measured using an auto-analyzer.

\section{Definitions}

Hypertension in Chinese adult was defined according to the "2018 Chinese guidelines for the management of hypertension [14]" as systolic blood pressure $(\mathrm{SBP}) \geq 140 \mathrm{~mm} \mathrm{Hg}$ and /or diastolic blood pressure $(\mathrm{DBP}) \geq 90 \mathrm{~mm} \mathrm{Hg}$, and/or use of antihypertensive medications. For adolescents $\geq 13$ years of age, "hypertension" was defined as $\mathrm{SBP} \geq 130 \mathrm{mmHg}$ and/or DBP $\geq 80 \mathrm{mmHg}$ [15]. Obesity was diagnosed according to the "Screening for Overweight and Obesity Among School-age Children and Adolescents" criteria: $\mathrm{BMI} \geq 27.1, \mathrm{BMI} \geq 27.6$, $\mathrm{BMI} \geq 28.0$ were the obesity criteria for adolescents aged 
$16,17,18$ years and older, respectively. Criteria for abnormal liver enzymes for adolescents $<18$ years of age were ALT $>30 \mathrm{U} / \mathrm{L}$ for boys and $>21 \mathrm{U} / \mathrm{L}$ for girls, AST $>38$ $\mathrm{U} / \mathrm{L}$ for boys and $>33 \mathrm{U} / \mathrm{L}$ for girls [16]. The upper limit of normal serum ALT level and AST levels both were set at $40 \mathrm{U} / \mathrm{L}$ in adults, and an elevated ALT level was defined as $>40 \mathrm{U} / \mathrm{L}$, and elevated AST was defined as $>40$ U/L [17]. Serum ALT levels were categorized by quartiles as $\leq 9,10-12,13-18$, and $\geq 19$ U/L. Serum AST levels were categorized by quartiles as $\leq 17,18-20,21-23$, and $\geq 24 \mathrm{U} / \mathrm{L}$.

\section{Statistical analysis}

We calculated the mean \pm standard deviation (SD) for continuous data and frequency (percentage) for categorical variables. The independent-samples t-test was performed to compare the differences in continuous variables. The categorical variable distributions were compared using Chi-square tests. Pearson correlation was used to evaluate the relationship between ALT and AST levels and other variables. Multivariate logistic regression models adjusted for age and sex (Model 1) or age, sex, BMI, smoking, and drinking (Model 2) or Model 2 plus, TC, TG, HDL-C, LDL-C, and GLU were used to estimate the odds ratios (ORs) of the associations between ALT and AST and hypertension. All statistical analyses were conducted using SPSS software (version 18.0; SPSS Inc., Chicago, IL, USA). Statistical significance was defined as a two-tailed $P<0.05$.

\section{Results}

Baseline characteristics of this study

The baseline characteristics of the study population according to sex are presented in Table 1. A total of 3114 freshmen (1264 men and 1850 women) participated in the study. The mean age was $18.52 \pm 1.01$ years (range 15-27 years). The overall prevalence of elevated ALT and AST were $6.8 \%(n=211), 2.3 \%(n=71)$ among freshmen. The mean ALT and AST levels were higher in males $(22.59 \pm 21.98$ vs.12.62 $\pm 10.30 \mathrm{U} / \mathrm{L} ; 23.55 \pm 12.24$ vs. $20.02 \pm 5.75 \mathrm{U} / \mathrm{L}$, respectively). Male freshmen had a significantly higher prevalence of hypertension (16.1\%) than female freshmen (1.9\%). Additionally, male participants had higher levels of BMI, SBP, DBP, TG, and LDL-C, but lower GLU, TC, and HDL-C levels than the females $(P<0.05)$.

\section{Prevalence of hypertension}

The overall prevalence of hypertension was $8.4 \%$ $(n=262)$. Participants with hypertension had higher BMI, TC, TG, LDL-C, ALT, and AST, and had lower HDL-C levels. The prevalence abnormal liver enzymes rate was significantly higher in the hypertensive group (ALT $21.0 \%$ vs. $5.5 \%$; AST $6.5 \%$ vs. $1.9 \%$; obesity $30.9 \%$ vs. $10.5 \%, P<0.05)$ than in the normotensive group. In males, the mean ALT and AST concentration were higher in those with hypertension. In contrast, no differences were observed among the female participants (Table 2).

Table 1 Characteristics of the study participants

\begin{tabular}{|c|c|c|c|c|c|}
\hline Characteristic & Total $(n=3114)$ & Males $(n=1264)$ & Females $(n=1850)$ & $t / x^{2}$ & $P$ \\
\hline Age (year) & $18.52 \pm 1.01$ & $18.57 \pm 1.01$ & $18.48 \pm 1.01$ & 2.417 & 0.016 \\
\hline BMI $\left(\mathrm{kg} / \mathrm{m}^{2}\right)$ & $22.33 \pm 3.53$ & $23.11 \pm 3.97$ & $21.8 \pm 3.09$ & 9.868 & 0.000 \\
\hline $\mathrm{SBP}(\mathrm{mmHg})$ & $114.05 \pm 13.73$ & $121.71 \pm 13.57$ & $108.81 \pm 11.14$ & 27.966 & 0.000 \\
\hline $\mathrm{DBP}(\mathrm{mmHg})$ & $70.94 \pm 10.56$ & $73.21 \pm 11.04$ & $69.38 \pm 9.92$ & 9.904 & 0.000 \\
\hline GLU (mmol/L) & $4.57 \pm 0.4$ & $4.51 \pm 0.38$ & $4.6 \pm 0.41$ & -6.271 & 0.000 \\
\hline $\mathrm{TC}(\mathrm{mmol} / \mathrm{L})$ & $4.05 \pm 0.68$ & $4.01 \pm 0.74$ & $4.08 \pm 0.63$ & -2.95 & 0.001 \\
\hline TG (mmol/L) & $0.83 \pm 0.4$ & $0.87 \pm 0.47$ & $0.81 \pm 0.35$ & 3.826 & 0.000 \\
\hline $\mathrm{HDL}-\mathrm{C}(\mathrm{mmol} / \mathrm{L})$ & $1.42 \pm 0.28$ & $1.31 \pm 0.25$ & $1.49 \pm 0.27$ & -18.915 & 0.000 \\
\hline LDL-C (mmol/L) & $2.09 \pm 0.56$ & $2.15 \pm 0.63$ & $2.05 \pm 0.5$ & 4.846 & 0.000 \\
\hline $\operatorname{ALT}(U / L)$ & $16.67 \pm 16.82$ & $22.59 \pm 21.98$ & $12.62 \pm 10.30$ & 15.035 & 0.000 \\
\hline AST (U/L) & $21.45 \pm 9.13$ & $23.55 \pm 12.24$ & $20.02 \pm 5.75$ & 9.566 & 0.000 \\
\hline Prevalence of elevated ALT (\%) & $211(6.8)$ & $154(12.2)$ & $57(3.1)$ & 98.498 & 0.000 \\
\hline Prevalence of elevated AST (\%) & $71(2.3)$ & $52(4.1)$ & $19(1.0)$ & 32.116 & 0.000 \\
\hline Current smoking status (\%) & $76(2.4)$ & $68(5.4)$ & $8(0.4)$ & 77.192 & 0.000 \\
\hline Current drinking status (\%) & $428(13.7)$ & $329(26.0)$ & $99(5.4)$ & 270.812 & 0.000 \\
\hline Prevalence of hypertension (\%) & $262(8.4)$ & $203(16.1)$ & $59(1.9)$ & 161.438 & 0.000 \\
\hline
\end{tabular}

BMI, body mass index; SBP, systolic blood pressure; DBP, diastolic blood pressure; GLU, glucose; TC, total cholesterol; TG, triglycerides; HDL-C, high-density lipoprotein cholesterol; LDL-C, low-density lipoprotein cholesterol; ALT, alanine aminotransferase; AST, aspartate aminotransferase 


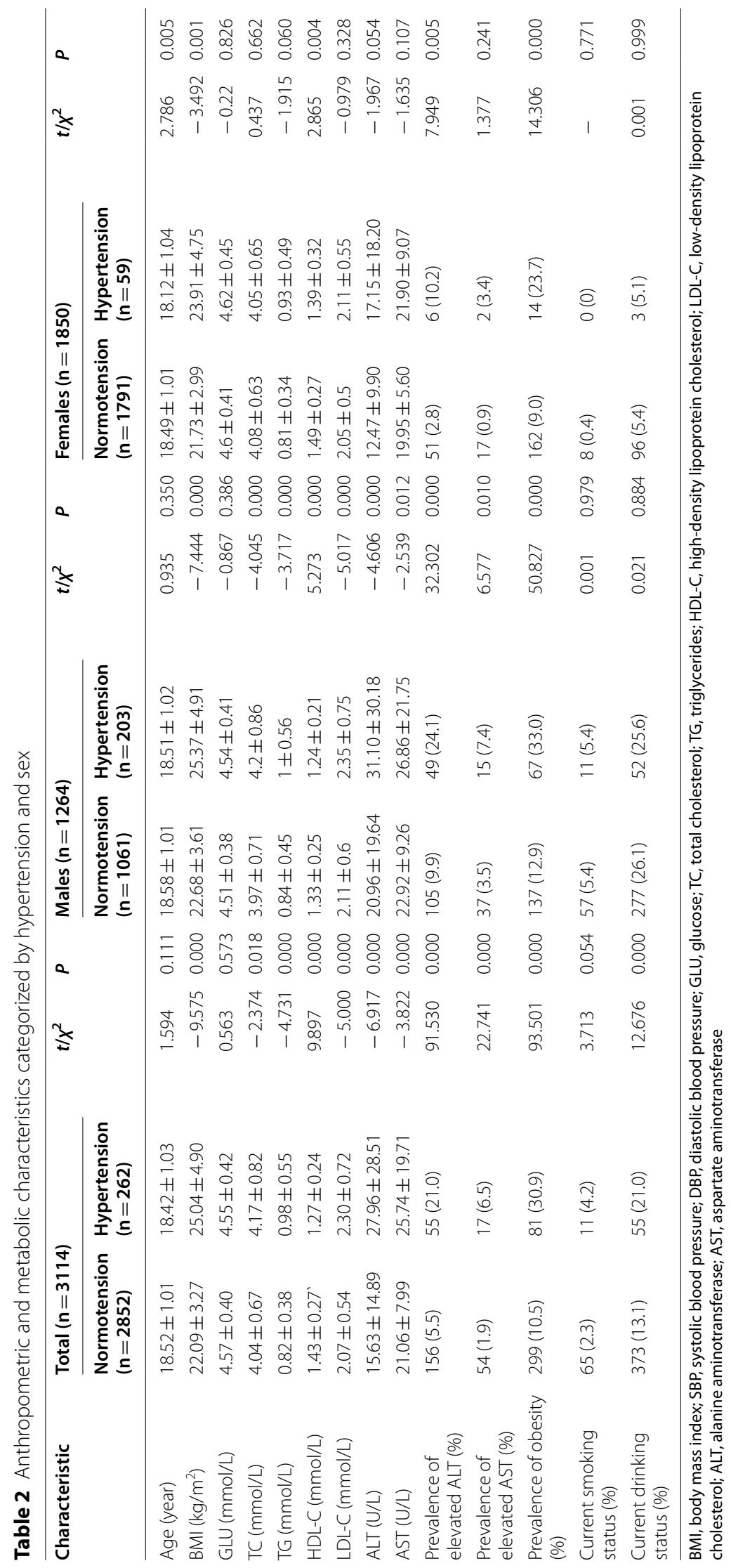




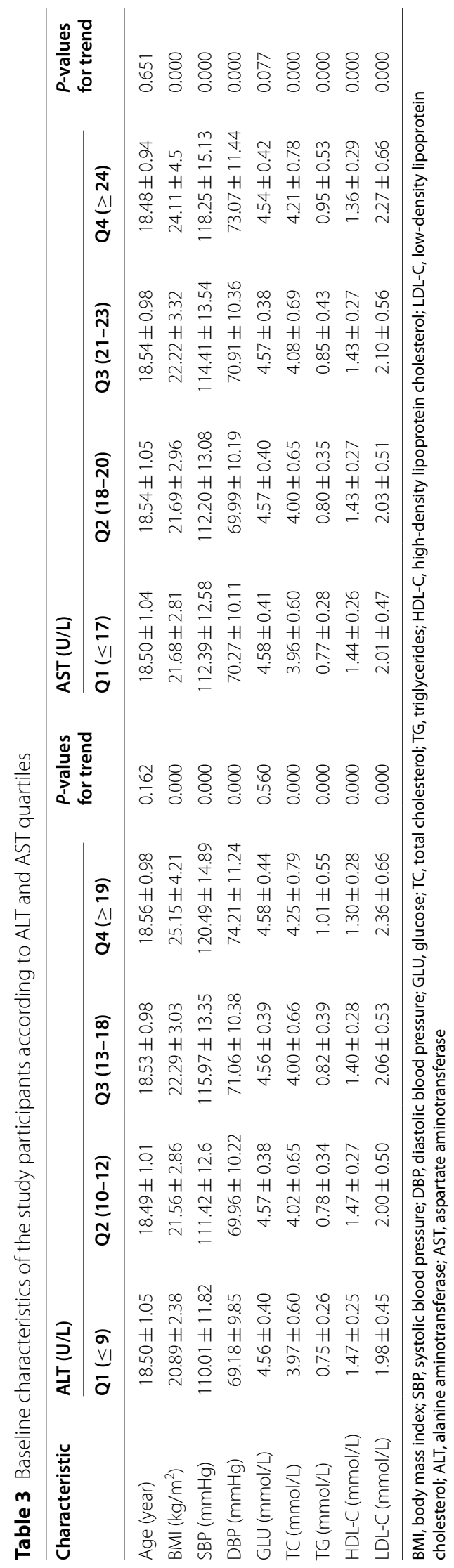


Table 4 Correlation between ALT and AST levels and hypertensive risk factors

\begin{tabular}{|c|c|c|c|c|c|c|c|c|c|c|c|c|}
\hline \multirow[t]{3}{*}{ Characteristic } & \multicolumn{6}{|l|}{ ALT } & \multicolumn{6}{|l|}{ AST } \\
\hline & \multicolumn{2}{|l|}{ Total } & \multicolumn{2}{|l|}{ Males } & \multicolumn{2}{|l|}{ Females } & \multicolumn{2}{|l|}{ Total } & \multicolumn{2}{|l|}{ Males } & \multicolumn{2}{|l|}{ Females } \\
\hline & $r$ & $P$ & $r$ & $P$ & $r$ & $P$ & $r$ & $P$ & $r$ & $P$ & $r$ & $P$ \\
\hline Age & 0.018 & 0.318 & 0.010 & 0.722 & 0.000 & 0.999 & -0.008 & 0.661 & -0.023 & 0.420 & -0.010 & 0.665 \\
\hline BMl & 0.451 & 0.000 & 0.511 & 0.000 & 0.295 & 0.000 & 0.264 & 0.000 & 0.291 & 0.000 & 0.156 & 0.000 \\
\hline SBP & 0.273 & 0.000 & 0.206 & 0.000 & 0.105 & 0.000 & 0.150 & 0.000 & 0.090 & 0.001 & 0.045 & 0.051 \\
\hline DBP & 0.177 & 0.000 & 0.172 & 0.000 & 0.088 & 0.000 & 0.093 & 0.000 & 0.069 & 0.014 & 0.058 & 0.013 \\
\hline GLU & 0.018 & 0.319 & 0.047 & 0.091 & 0.070 & 0.003 & -0.007 & 0.679 & 0.006 & 0.829 & 0.027 & 0.246 \\
\hline TC & 0.153 & 0.000 & 0.252 & 0.000 & 0.066 & 0.005 & 0.104 & 0.000 & 0.151 & 0.000 & 0.070 & 0.003 \\
\hline TG & 0.266 & 0.000 & 0.310 & 0.000 & 0.171 & 0.000 & 0.130 & 0.000 & 0.136 & 0.000 & 0.094 & 0.000 \\
\hline $\mathrm{HDL}-\mathrm{C}$ & -0.223 & 0.000 & -0.213 & 0.000 & -0.085 & 0.000 & -0.120 & 0.000 & -0.119 & 0.000 & -0.006 & 0.804 \\
\hline LDL-C & 0.258 & 0.000 & 0.311 & 0.000 & 0.139 & 0.000 & 0.156 & 0.000 & 0.177 & 0.000 & 0.089 & 0.000 \\
\hline
\end{tabular}

BMI, body mass index; SBP, systolic blood pressure; DBP, diastolic blood pressure; GLU, glucose; TC, total cholesterol; TG, triglycerides; HDL-C, high-density lipoprotein cholesterol; LDL-C, low-density lipoprotein cholesterol; ALT, alanine aminotransferase; AST, aspartate aminotransferase

\section{Levels of demographic and clinical variables in the serum ALT and AST quartiles}

Baseline information of the subjects in each serum ALT and AST quartile is presented in Table 3. The mean values of BMI, SBP, DBP, TC, TG, and LDL-C were found to be increased with elevated levels of serum ALT and AST in the quartiles.

$(P<0.05$ for trend).

\section{Correlation between ALT and AST levels and hypertensive risk factors}

Serum ALT levels were positively correlated with BMI, SBP and DBP in both genders $(r=0.511,0.207,0.172$, respectively; $P<0.05)$. Serum AST levels were positively correlated with BMI, SBP and DBP in males, but only with BMI and DBP in females $(P<0.05)$ (Table 4$)$.

\section{Association of ALT and AST with hypertension}

After adjusting for age and sex, the odd ratios (ORs) (95\% CI) were $1.774(1.139,2.762)$, and $3.047(2.028,4.578)$, respectively in Q3 and Q4 compared to Q1 of the ALT. After additionally adjusting obesity, smoking, and drinking, TC, TG, LDL-C, HDL-C, compared with those in the lowest quartile, individuals in the highest quartile of serum ALT levels had associated with hypertension in males and females, with an OR (95\% CI) of 1.681 (1.028, 2.751), and 2.802 (1.102, 7.124), respectively. However, there was no significant association of serum AST levels with hypertension in the full adjustment model (Table 5).

\section{Discussion}

In this study, we evaluated the relationship between ALT and AST levels and hypertension in a large, representative sample of 3114 freshmen. We demonstrated that only serum ALT, but not AST, was associated with hypertension both in males and females after adjusting for potential confounders.

In recent years, the incidence of abnormal ALT and AST has increased worldwide, making it a health issue $[18,19]$. The overall prevalence of elevated ALT and AST were $6.8 \%$ and $2.3 \%$ in our study. A school-based crosssectional study in China reported a prevalence of $6.76 \%$ for ALT levels greater than $30 \mathrm{U} / \mathrm{L}$ for boys and $9 \mathrm{U} / \mathrm{L}$ for girls, compared with $2.43 \%$ at a cut-off level of greater than $40 \mathrm{U} / \mathrm{L}$ [20]. Asymptomatic elevation in ALT levels is common in primary care, and the prevalences of elevated ALT and AST in the United States were 8.9\%, $4.9 \%$ respectively [21]. Freshmen are a special group and some biomarker levels are quite different from those of healthy adults [22]. This study shows that the prevalence of elevated ALT and AST levels differed in gender among freshman of China. Male freshmen had a significantly higher prevalence of elevated ALT and AST than female freshmen. We should take the prevalence as a predictor and continue to play a warning and preventive role.

ALT refers to an enzyme that is largely found in the liver. When the liver is damaged, ALT will be sent to the bloodstream, signalling liver disease, and ALT level in blood is used as an indication of the liver status, giving information about the seriousness of liver damage. Although AST is a marker of hepatocellular health, it is a less specific marker of liver function than ALT [23]. Our results revealed the SBP and DBP were increasing along with serum ALT and AST elevating whether in females or males populations. However, in regression analysis, only ALT was significantly associated with hypertension even after adjustment of potential confounders. A similar finding was observed in a previous study that only serum 
Table 5 Association of ALT and AST with hypertension

\begin{tabular}{|c|c|c|c|c|}
\hline Group & Characteristic & Model 1 & Model 2 & Model 3 \\
\hline \multirow[t]{12}{*}{ Total } & ALT & & & \\
\hline & $\mathrm{Q} 1(\leq 9)$ & 1 & 1 & 1 \\
\hline & Q2 (10-12) & $1.575(0.992,2.500)$ & $1.517(0.955,2.409)$ & $1.511(0.950,2.402)$ \\
\hline & Q3 (13-18) & $1.774(1.139,2.762)^{*}$ & $1.614(1.033,2.523)^{*}$ & $1.545(0.986,2.420)$ \\
\hline & Q4 ( $\geq 19)$ & $3.047(2.028,4.578)^{*}$ & $2.111(1.365,3.266)^{*}$ & $1.815(1.157,2.846)^{*}$ \\
\hline & $P$ for trend & 0.000 & 0.001 & 0.014 \\
\hline & AST & & & \\
\hline & $\mathrm{Q} 1(\leq 17)$ & 1 & 1 & 1 \\
\hline & Q2 (18-20) & $1.446(0.964,2.167)$ & $1.471(0.979,2.212)$ & $1.435(0.953,2.162)$ \\
\hline & Q3 (21-23) & $1.479(0.966,2.264)$ & $1.354(0.879,2.085)$ & $1.329(0.860,2.054)$ \\
\hline & Q4 ( $\geq 24)$ & $2.000(1.355,2.953)^{*}$ & $1.502(1.001,2.254)^{*}$ & $1.388(0.917,2.099)$ \\
\hline & $P$ for trend & 0.001 & 0.102 & 0.219 \\
\hline \multirow[t]{12}{*}{ Males } & ALT & & & \\
\hline & $\mathrm{Q} 1(\leq 11)$ & 1 & 1 & 1 \\
\hline & Q2 (12-16) & $1.409(0.884,2.243)$ & $1.319(0.826,2.107)$ & $1.245(0.776,1.966)$ \\
\hline & Q3 (17-25) & $1.401(0.874,2.245)$ & $1.166(0.718,1.893)$ & $1.031(0.630,1.688)$ \\
\hline & Q4 ( $\geq 26)$ & $3.139(2.076,4.746)^{*}$ & $2.033(1.274,3.245)^{*}$ & $1.681(1.028,2.751)^{*}$ \\
\hline & $P$ for trend & 0.000 & 0.006 & 0.076 \\
\hline & AST & & & \\
\hline & $\mathrm{Q} 1(\leq 18)$ & 1 & 1 & 1 \\
\hline & Q2 (19-21) & $1.152(0.731,1.814)$ & $1.121(0.708,1.776)$ & $1.098(0.691,1.746)$ \\
\hline & Q3 (22-25) & $1.533(0.991,2.371)$ & $1.33(0.852,2.077)$ & $1.275(0.81,2.009)$ \\
\hline & Q4 ( $\geq 26)$ & $1.88(1.233,2.868)^{*}$ & $1.276(0.812,2.007)$ & $1.151(0.725,1.828)$ \\
\hline & $P$ for trend & 0.001 & 0.224 & 0.462 \\
\hline \multirow[t]{12}{*}{ Females } & ALT & & & \\
\hline & $\mathrm{Q} 1(\leq 7)$ & 1 & 1 & 1 \\
\hline & Q2 (8-9) & $1.442(0.508,4.094)$ & $1.421(0.499,4.040)$ & $1.430(0.502,4.071)$ \\
\hline & Q3 (10-13) & $2.660(1.062,6.662)^{*}$ & $2.453(0.976,6.170)$ & $2.516(0.996,6.356)$ \\
\hline & Q4 ( $\geq 14)$ & $3.444(1.386,8.557)^{*}$ & $2.916(1.157,7.351)^{*}$ & $2.802(1.102,7.124)^{*}$ \\
\hline & $P$ for trend & 0.002 & 0.008 & 0.012 \\
\hline & AST & & & \\
\hline & $\mathrm{Q} 1(\leq 16)$ & 1 & 1 & 1 \\
\hline & Q2 (17-19) & $1.721(0.724,4.093)$ & $1.794(0.751,4.283)$ & $1.784(0.747,4.263)$ \\
\hline & Q3 (20-21) & $1.398(0.514,3.802)$ & $1.409(0.516,3.846)$ & $1.409(0.514,3.865)$ \\
\hline & $\mathrm{Q} 4(\geq 22)$ & $2.554(1.077,6.055)^{*}$ & $2.395(1.005,5.711)^{*}$ & $2.398(0.998,5.763)$ \\
\hline & $P$ for trend & 0.042 & 0.076 & 0.078 \\
\hline
\end{tabular}

Model 1: Adjusted for age, gender

Model 2: Adjusted for model 1 plus, obesity (based on BMI), smoking and drinking Model 3: Adjusted for model 2 plus, TC, TG, HDL, LDL

*Compared to Q1, $P<0.05$

ALT showed an independent relationship with hypertension [24]. More and more studies have shown that ALT play a considerable role in the development of cardiovascular diseases [18, 25]. Besides, ALT is associated with endothelial dysfunction and coronary heart disease [26]. A Korea Medical Insurance Corporation study showed that an elevated ALT is a predictor of intracerebral hemorrhage [27]. A longitudinal increase in ALT activity increases the incidence of metabolic syndrome [28]. Elevated plasma ALT levels were associated with hypertension at baseline in the Hong Kong Cardiovascular Risk Factor Prevalence Study. For participants who were not on antihypertensive medications, the plasma ALT level correlated with high blood pressure [29].

Although the mechanism underlying the associations between ALT and hypertension remains unclear, some 
mechanisms can be considered, and one of the most plausible is non-alcoholic fatty liver disease (NAFLD). Elevated serum ALT levels reflect an excess deposit of fat in the liver and are commonly used as a surrogate marker for NAFLD in epidemiological studies [30]. NAFLD represents the hepatic manifestation of the metabolic syndrome, which refers to a variably defined aggregate of disorders related to obesity, hypertension, type 2 diabetes, and hyperlipidemia [31]. Lopez-Suarez A et al. [32] indicated that NAFLD is associated with an independent risk of identifying hypertension and high-normal SBP. Detection of NAFLD, even with normal ALT levels, should serve as an opportunity to identify metabolic and BP abnormalities. Overweight and obesity are associated with elevated biochemical markers of liver damage, and obesity is well-known major predisposing conditions to NAFLD [33]. Children and adolescents who are overweight or obese have shown higher ALT concentrations in all age groups [34]. Our results also showed that ALT had the strongest correlation with BMI than other hypertension risk factors. A study of Poland middle and high school students aged 15-17 found that BMI is one of the strongest predictors of hypertension in teenagers [35]. A previous study revealed that an increase in BMI is linked to hypertension in university students [36]. Obesity may lead to hypertension in multiple ways by different percents [37]. It is speculated that high ALT levels will lead to an increase in BMI, which in turn leads to hypertension. Other possibility is that elevated serum ALT is a marker of inflammation and oxidative stress, and oxidative stress may play an important role in the initiation and progression of hypertension [38]. Finally, insulin resistance is the most common abnormality associated with the pathogenesis of both ALT and hypertension. ALT is associated with insulin resistance [39], and insulin resistance is commonly detected in individuals with hypertension [40].

We present the gender-specific analysis for the association between increasing liver enzymes levels and hypertension. In our logistic regression analysis, after adjusting for hypertensive risk factors, the risk of hypertension was significantly higher in the highest ALT quartile than in the lowest quartile in both sexes. However, a clear linear association between ALT and hypertension was present only among females. We did not observe an association between elevated serum AST levels and hypertension. One reason for the lack of linear association between ALT and hypertension in males may be related to sex differences in the absolute risk of hypertension. Research has reported that the gender difference of blood pressure began to appear in adolescence, and pubertal growth spurt occurs earlier for females than for males [41]. Thus, the relationship between ALT levels and hypertension in males needs to be further investigated.

The limitations of this study are as follows. First, this was a cross-sectional study, and causality could not be determined. Thus, further prospective studies are needed to verify the causal relationship between ALT and the prevalence of hypertension. Second, the study participants were all freshmen, so the results may not be generalizable to students of other age groups.

\section{Conclusions}

Results of this study suggest that serum ALT but not AST levels were positively associated with the prevalence of hypertension in both sexes. A linear association between elevated serum ALT and hypertension only in total population and females. To understand the complex interaction between ALT and hypertension, a large, wellconstructed prospective study to elucidate the association between these factors is indicated.

\begin{abstract}
Abbreviations
ALT: Alanine aminotransferase; AST: Aspartate aminotransferase; BMI: Body mass index; BP: Blood pressure; SBP: Systolic blood pressure; DBP: Diastolic blood pressure; GLU: Glucose; TC: Total cholesterol; TG: Triglycerides; HDL-C: High-density lipoprotein cholesterol; LDL-C: Low-density lipoprotein cholesterol; UA: Uric acid.
\end{abstract}

\section{Acknowledgements}

We thank all participants and teaching staff from School of Public Health, Wannan Medical College for their assistance and support.

\section{Authors' contributions}

LZ and ZF conducted the experiments. LZ managed and analyzed the data and wrote the manuscript. $\mathrm{MH}$ and $\mathrm{YJ}$ were one of the principal investigators of the study. WC and LH revised the manuscript. YC was a contributor in organizing the database. $Y C$ and $Y Y$ reviewed the manuscript. All authors read and approved the final manuscript.

\section{Funding}

This work was supported by the National Natural Science Foundation of China (Grant No. 81874280, No. 81673266 and No.82003546); The Fifth Batch of Talents Selected under the Special Support Plan in Anhui Provence (Organization Department of Anhui provincial Party committee, [2019] No.14; T000516); Anhui Provincial Natural Science Foundation (No. 1808085QH283, No.

1808085MH297); Key Projects of Anhui Provincial Department of Education (No. KJ2019A0404, No. KJ2019A0405).

\section{Availability of data and materials}

The datasets during and/or analyzed during the current study will be available from the corresponding author on reasonable request.

\section{Declarations}

\section{Ethics approval and consent to participate}

The study was approved by the Ethics Committee of the First Affiliated Yijishan Hospital of Wannan Medical College (Approval No. 32 (2018)). All procedures performed in studies involving human participants were in accordance with the ethics standards of the institutional and national research committee and with the Declaration of Helsinki. Written informed consent was obtained from all participants or, if subjects are under 18, from a parent and/or legal guardian. 


\section{Consent for publication \\ Not applicable.}

\section{Competing interests}

The authors declare no conflict of interest.

\section{Author details}

${ }^{1}$ Department of Epidemiology and Biostatistics, School of Public Health, Wannan Medical College, No. 22, Wenchang Road, Wuhu 241002, Anhui, China. ${ }^{2}$ Institute of Chronic Disease Prevention and Control, Wannan Medical College, No. 22, Wenchang Road, Wuhu 241002, Anhui, China. ${ }^{3}$ School of Medicine, Taizhou University, Taizhou 318000, China. ${ }^{4}$ Department of Medicine, Anhui College of Traditional Chinese Medicine, No.18, Wuxia Shanxi Road, Wuhu 241002, Anhui, China.

Received: 26 May 2021 Accepted: 24 September 2021 Published online: 01 October 2021

\section{References}

1. GBD 2017 Causes of Death Collaborators. Global, regional, and national age-sex-specific mortality for 282 causes of death in 195 countries and territories, 1980-2017: a systematic analysis for the Global Burden of Disease Study 2017. Lancet. 2018;392(10159):1736-88.

2. De Venecia T, Lu M, Figueredo VM. Hypertension in young adults. Postgrad Med. 2016;128(2):201-7.

3. Wang C, Yuan Y, Zheng M, Pan A, Wang M, Zhao M, Li Y, Yao S, Chen S, Wu $S$, et al. Association of age of onset of hypertension with cardiovascular diseases and mortality. J Am Coll Cardiol. 2020;75(23):2921-30.

4. Jia J, Yang Y, Liu F, Zhang M, Xu Q, Guo T, Wang L, Peng Z, He Y, Wang $Y$, et al. The association between serum alanine aminotransferase and hypertension: a national based cross-sectional analysis among over 21 million Chinese adults. BMC Cardiovasc Disord. 2021;21(1):145.

5. Liang $X$, Zhong $H$, Xiao $L$. The effect of community hypertension management on blood pressure control and its determinants in southwest China. Int Health. 2020;12(3):203-12.

6. Hong X, Wongtongkam N, Ward PR, Xiao S, Wang S, Peng Q, Zuo Q, Zeng D, Wang J, Wang C, et al. An association of serum ALT with elevated blood pressure in senior adults: a case-control study. Clin Exp Hypertens. 2016;38(8):691-5

7. Yu ES, Hong K, Chun BC. Incidence and risk factors for progression from prehypertension to hypertension: a 12-year Korean Cohort Study. J Hypertens. 2020;38(9):1755-62.

8. Porter SA, Pedley A, Massaro JM, Vasan RS, Hoffmann U, Fox CS. Aminotransferase levels are associated with cardiometabolic risk above and beyond visceral fat and insulin resistance: the Framingham Heart Study. Arterioscler Thromb Vasc Biol. 2013;33(1):139-46.

9. Gupta A, Panthari M, Ahmad N, Nagtilak S, Nandwani S. Levels of Alanine Aminotransferase (ALT), Aspartate Amino transferase (AST) and Gamma Glutamyl Transferase (GGT) in hypertension. Biomed Res. 2013;24(1):59-61

10. Haidar SA, de Vries NK, Papandreou D, Rizk R, Karavetian M. The freshman weight gain phenomenon: does it apply to. Open Access Maced J Med Sci. 2018;6(11):2214-20.

11. Tsai PY, Yen CJ, Li YC, Chiu TY, Chen CY, Jan CF. Association between abnormal liver function and risk factors for metabolic syndrome among freshmen. J Adolesc Health: Off Publ Soc Adolesc Med. 2007;41(2):132-7.

12. Lang J, Jin L, Liu L, Yao Y. Prevalence of hypertension among Chinese college students: a meta-analysis. Chin J Sch Health. 2018;39(08):1220-3.

13. Abiodun O, Ladele A, Olu-Abiodun O, Ashipa T. Hypertension among adolescents in Nigeria: a retrospective study of adolescent university freshmen. Int J Adolesc Med Health. 2019. https://doi.org/10.1515/ ijamh-2018-0287.

14. Writing Group of 2018 Chinese Guidelines for the Management of Hypertension CHL, Chinese Society of Cardiology, Chinese Medical Doctor Association Hypertension Committee, Hypertension Branch of China International Exchange and Promotive Association for Medical and Health Care, Hypertension Branch of Chinese Geriatric Medical Association. 2018 Chinese Guidelines for the Management of Hypertension. Chin J Cardiovasc Med. 2019;24(01):24-56.
15. Flynn JT, Kaelber DC, Baker-Smith CM, Blowey D, Carroll AE, Daniels SR, de Ferranti SD, Dionne JM, Falkner B, Flinn SK, et al. Clinical practice guideline for screening and management of high blood pressure in children and adolescents. Pediatrics. 2017;140(3):e20171904

16. Poustchi H, George J, Esmaili S, Esna-Ashari F, Ardalan G, Sepanlou SG, Alavian SM. Gender differences in healthy ranges for serum alanine aminotransferase levels in adolescence. PLoS ONE. 2011;6(6):e21178.

17. Lai M, Hyatt BJ, Nasser I, Curry M, Afdhal NH. The clinical significance of persistently normal ALT in chronic hepatitis B infection. J Hepatol. 2007;47(6):760-7

18. Bekkelund SI. Serum alanine aminotransferase activity and risk factors for cardiovascular disease in a Caucasian population: the Tromso study. BMC Cardiovasc Disord. 2021;21(1):29.

19. Ndrepepa G, Holdenrieder S, Cassese S, Xhepa E, Fusaro M, Laugwitz $\mathrm{KL}$, Schunkert H, Kastrati A. Aspartate aminotransferase and mortality in patients with ischemic heart disease. Nutr Metab Cardiovasc Dis. 2020;30(12):2335-42.

20. Zhang J, Wang ZY, Zhang JP, Zhou H, Ding Z. Prevalence of elevated alanine aminotransferase by diagnostic criterion, age, and gender among adolescents. Gastroenterol Res Pract. 2020;2020:4240380.

21. Ioannou GN, Boyko EJ, Lee SP. The prevalence and predictors of elevated serum aminotransferase activity in the United States in 1999-2002. Am J Gastroenterol. 2006;101(1):76-82.

22. Adeli K. Closing the gaps in pediatric reference intervals: the CALIPER initiative. Clin Biochem. 2011;44(7):480-2.

23. Xu Q, Higgins T, Cembrowski GS. Limiting the testing of AST: a diagnostically nonspecific enzyme. Am J Clin Pathol. 2015;144(3):423-6.

24. Rahman S, Islam S, Haque T, Kathak RR, Ali N. Association between serum liver enzymes and hypertension: a cross-sectional study in Bangladeshi adults. BMC Cardiovasc Disord. 2020;20(1):128.

25. Yokoyama M, Watanabe T, Otaki Y, Takahashi H, Arimoto T, Shishido T, Miyamoto T, Konta T, Shibata Y, Daimon M, et al. Association of the aspartate aminotransferase to alanine aminotransferase ratio with BNP level and cardiovascular mortality in the general population: the Yamagata Study 10-year follow-up. Dis Markers. 2016;2016:4857917.

26. Schindhelm RK, Dekker JM, Nijpels G, Bouter LM, Stehouwer CD, Heine RJ, Diamant M. Alanine aminotransferase predicts coronary heart disease events: a 10-year follow-up of the Hoorn Study. Atherosclerosis. 2007;191(2):391-6.

27. Kim HC, Kang DR, Nam CM, Hur NW, Shim JS, Jee SH, Suh I. Elevated serum aminotransferase level as a predictor of intracerebral hemorrhage: Korea medical insurance corporation study. Stroke. 2005;36(8):1642-7.

28. Sun H, Liu Q, Wang X, Li M, Fan Y, Song G, Liu Y. The longitudinal increments of serum alanine aminotransferase increased the incidence risk of metabolic syndrome: a large cohort population in China. Clin Chim Acta; Int J Clin Chem. 2019;488:242-7.

29. Cheung BM, Ong KL, Tso AW, Cherny SS, Sham PC, Lam TH, Lam KS. Gamma-glutamyl transferase level predicts the development of hypertension in Hong Kong Chinese. Clin Chim Acta; Int J Clin Chem. 2011;412(15-16):1326-31

30. Chang $Y$, Ryu S, Sung $E$, Jang $Y$. Higher concentrations of alanine aminotransferase within the reference interval predict nonalcoholic fatty liver disease Clin Chem. 2007:53(4):686-92.

31. Brunt EM. Nonalcoholic steatohepatitis. Semin Liver Dis. 2004;24(1):3-20.

32. Lopez-Suarez A, Guerrero JM, Elvira-Gonzalez J, Beltran-Robles M, Canas-Hormigo F, Bascunana-Quirell A. Nonalcoholic fatty liver disease is associated with blood pressure in hypertensive and nonhypertensive individuals from the general population with normal levels of alanine aminotransferase. Eur J Gastroenterol Hepatol. 2011;23(11):1011-7.

33. Finelli $C$, Tarantino $G$. What is the role of adiponectin in obesity related non-alcoholic fatty liver disease? World J Gastroenterol. 2013;19(6):802-12.

34. Johansen MJ, Gade J, Stender S, Frithioff-Bojsoe C, Lund MAV, Chabanova E, Thomsen HS, Pedersen O, Fonvig CE, Hansen T, et al. The effect of overweight and obesity on liver biochemical markers in children and adolescents. J Clin Endocrinol Metab. 2020;105(2):430-42.

35. Wieniawski P, Werner B. Prediction of the hypertension risk in teenagers. Cardiol J. 2020. https://doi.org/10.5603/CJ.a2020.0079.

36. Uchiyama A, Shimizu T, Nakagawa T, Tanaka T. Association of hypertension with changes in the body mass index of university students. Environ Health Prev Med. 2008;13(5):271-80. 
37. Wu O, Leng $J H$, Yang FF, Yang HM, Zhang H, Li ZF, Zhang XY, Yuan CD, Li $J$ J, Pan Q, et al. A comparative research on obesity hypertension by the comparisons and associations between waist circumference, body mass index with systolic and diastolic blood pressure, and the clinical laboratory data between four special Chinese adult groups. Clin Exp Hypertens. 2018;40(1):16-21.

38. Yamada J, Tomiyama H, Yambe M, Koji Y, Motobe K, Shiina K, Yamamoto Y, Yamashina A. Elevated serum levels of alanine aminotransferase and gamma glutamyltransferase are markers of inflammation and oxidative stress independent of the metabolic syndrome. Atherosclerosis. 2006;189(1):198-205.

39. Hanley AJ, Wagenknecht LE, Festa A, D'Agostino RB Jr, Haffner SM. Alanine aminotransferase and directly measured insulin sensitivity in a multiethnic cohort: the Insulin Resistance Atherosclerosis Study. Diabetes Care. 2007;30(7):1819-27.

40. Saad MF, Rewers M, Selby J, Howard G, Jinagouda S, Fahmi S, Zaccaro D, Bergman RN, Savage PJ, Haffner SM. Insulin resistance and hypertension: the Insulin Resistance Atherosclerosis study. Hypertension. 2004;43(6):1324-31.

41. Ewald DR, Haldeman LA. Risk factors in adolescent hypertension. Global Pediatric Health. 2016;3:2333794X15625159.

\section{Publisher's Note}

Springer Nature remains neutral with regard to jurisdictional claims in published maps and institutional affiliations.
Ready to submit your research? Choose BMC and benefit from:

- fast, convenient online submission

- thorough peer review by experienced researchers in your field

- rapid publication on acceptance

- support for research data, including large and complex data types

- gold Open Access which fosters wider collaboration and increased citations

- maximum visibility for your research: over 100M website views per year

At BMC, research is always in progress.

Learn more biomedcentral.com/submissions 